A noticeable feature of this eclipse has been the misleading effect of meteorological statistics as influencing the observers' choice of sites for their stations. The eclipse was observed under almost perfect conditions from Padang Pandjang, which is regarded as the rainiest and cloudiest region in Sumatra, while those who camped in the old Soluk Fort were the least favoured on the entire coast.

The Twelve Movements of the Earth. - In the Bulletin de la Soc. Ast. de France (1901, pp. 262-266), M. Flammarion gives an interesting review of the various movements by which the terrestrial sphere is known to be affected at the present time. These are due to, or consist of, the following phenomena :-

(I) Rotation, having a period of 24 hours.

(2) Revolution, having a period of $365 \frac{1}{4}$ days.

(3) Precession, having a period of 25,765 years.

(4) Luni-solar gravitation, having a period of 28 days.

(5) Nutaticn, having a period of $18 \frac{1}{2}$ years.

(6) Variation of obliquity of ecliptic, about $47^{\prime \prime}$ arc in 100 years.

(7) Variation of eccentricity of orbit.

(8) Change of line of apsides, period about 21,000 years.

(9) Planetary perturbations.

(Io) Change of centre of gravity of whole solar system.

(II) General translation of solar system in space.

(I2) Latitude variation with several degrees of periodicity.

New Nebula.-In the Comptes rendus (vol. cxxxiii. pp. 2628 and 86-88), M. G. Bigourdan gives two further lists of new nebula discovered with the west equatorial at the Paris Observa'ory. The first paper deals with twenty-one objects, observed during the period 1897-1899, copious notes and comparisons with the N.G.C. being appended.

The second list contains similar information regarding nineteen nebulæ observed between 1884 and 1898 .

\section{THE SUPPRESSION OF TUBERCULOSIS.}

THE task with which this Congress will have to busy itself is one of the most difficult, but it is also one in which labour is most sure of its reward.

I need not point again to the innumerable victims tuberculosis annually claims in all countries, or to the boundless misery it brings on the families it attacks. You all know that there is no disease which inflicts such deep wounds on mankind as this. All the greater, however, would be the general joy and satisfaction if the efforts that are being made to rid mankind of this enemy, which consumes its inmost marrow, were crowned with success.

There are many, indeed, who doubt the possibility or success. fully combating this disease, which has existed for thousand of years, and has spread all over the world. This is by no means my opinion. This is a conflict into which we may enter with a surely founded prospect of success, and I will tell you the reasons on which I base this conviction.

Only a few decades ago the real nature of tuberculosis was unknown to us; it was regarded as a consequence, as the expression, so to speak, of social misery, and, as this supposed cause could not be got rid of by simple means, people relied on the probable gradual improvement of social conditions, and did nothing. All this is altered now. We know that social misery does indeed go far to foster tuberculosis, but the real cause of the disease is a parasite - that is, a visible and palpable enemy, which we can pursue and annihilate, just as we can pursue and annihilate other parasitic enemies of mankind.

Strictly speaking, the fact that tuberculosis is a preventible disease ought to have become clear as soon as the tuberclebacillus was discovered, and the properties of this parasite and the manner of its transmission became known. I may add that I, for my part, was aware of the full significance of this discovery from the first, and so will everybody have been who had convinced himself of the causal relation between tuberculosis and the tubercle-bacillus. But the strength of a small number of medical men was inadequate to the conflict with a disease so deeply rooted in our habits and customs. Such a conflict requires the cooperation of many, if possible of all, medical men, shoulder to shoulder with the State and the whole population;

1 Paper on "The Combating of Tuberculosis in the Light of the Experience that has been gained in the Successful Combating of other In ectious Diseases," by Prof. Robert Koch, read at the British Congress on Tuberculosis, July 23 .

$$
\text { NO. I656, VOL. 64] }
$$

but now the moment when such cooperation is possible seems to have come. I suppose there is hardly any medical man now who denies the parasitic nature of tuberculosis, and among the non-medical public, too, the knowledge of the nature of the disease has been widely propagated.

Another favourable circumstance is that success has recently been achieved in the combating of several parasitic diseases, and that we have learned from these examples how the conflict with pestilences is to be carried on.

The most important lesson we have learned from the said ex. perience is that it is a great blunder to treat pestilences uniformly. This was done in former times; no matter whether the pestilence in question was cholera, plague, or leprosy : isolation, quarantine, useless disinfection were always rescrted to. But now we know that every disease must be treated according to its own special individuality, and that the measures to be taken against it must be most accurately adapted to its special nature, to its etiology. We are entitled to hope for success in combating tuberculosis only if we keep this lesson constantly in view. As so extremely much depends just on this point, I shall take the liberty to illustrate it by several examples.

The pestilence which is at this moment in the foreground of interest, the bubonic plague, may be instructive to us in several respects.

People used to act upon the conviction that a plague patient was in the highest degree a centre of infection, and that the disease was transmitted only by plague patients and their belongings. Even the most recent international agreements are based on this conviction. Although, as compared with formerly, we now have the great advantage that we can, with the aid of the microscope and of experiments on animals, recognise every case of plague with absolute certainty, and although the prescribed inspection of ships, quarantine, the isolation of patients, the disinfection of infected dwellings and ships are carried out with the utmost care, the plague has, nevertheless, been transmitted everywhere, and has in not a few places assumed grave dimensions. Why this has happened we know very well, owing to the experience quite recently gained as to the manner in which the plague is transmitted. It has been discovered that only those plague patients that suffer from plague-pneumoniaa condition which is fortunately infrequent-are centres of in. fection, and that the real transmitters of the plague are the rats. There is no longer any doubt that, in by far the majority of the cases in which the plague has been transmitted by ocean traffrc, the transmission took place by means of plague among the ship rats. It has also been found that, wherever the rats were in. tentionally or unintentionally exterminated, the plague rapidly disappeared; whereas at other places, where too little attention had been paid to the rat plague, the pestilence continued. This connection between the human plague and the rat plague was totally unknown before, so that no blame attaches to those who devised the measures now in force against the plague if the said measures have proved unavailing. It is high time, however, that this enlarged knowledge of the etiology of the plague be utilised in international as well as in other traffic. As the human plague is so dependent on the rat plague, it is intelligible that protective inoculation and the application of antitoxic serum have had so little effect. A certain number of human beings may have been saved from the disease by that, but the general spread of the pestilence has not been hindered in the east.

With cholera the case is essentially different ; it may, under certain circumstances, be transmitted directly from human beings to other human beings, but its main and most dangerous propagator is water, and therefore, in the combating of cholera, water is the first thing to be considered. In Germany, where this principle has been acted on, we have succeeded for four years in regularly exterminating the pestilence (which was introduced again and again from the infected neighbouring countries) without any obstruction of traffic.

Hydrophobia, too, is not void of instruction for us. Against this disease the so-called protective inoculation proper has proved eminently effective as a means of preventing the outbreak of the disease in persons already infected, but, of course, such a measure can do nothing to prevent infection itself. The only real way of combating this pestilence is by compulsory muzzling. In this matter also we have had the most satisfactory experience in Germany, but have at the same time seen that the total extermination of the pestilence can be achieved only by international measures, because hydrophobia, which can be very 
easily and rapidly suppressed, is always introduced again year after year from the neighbouring countries.

Permit me to mention only one other disease, because it is etiologically very closely akin to tuberculosis, and we can learn not a little for the furtherance of our aims from its successful combating. I mean leprosy. It is caused by a parasite which greatly resembles the tubercle-bacillus. Just like tuberculosis, it does not break out till long after infection, and its course is almost slower. It is transmitted only from person to person, but only when they come into close contact, as in small dwellings and bedrooms. In this disease, accordingly, immediate transmission plays the main part: transmission by animals, water, or the like is out of the question. The combative measures, accordingly, must be directed against this close intercourse between the sick and the healthy. The only way to prevent this intercourse is to isolate the patients. This was most rigorously done in the Middle Ages by means of numerous leper-houses, and the consequence was that leprosy, which had spread to an alarming extent, was completely stamped out in Central Europe. The same method has been adopted quite recently in Norway, where the segregation of lepers has been ordered by a special law. But it is extremely interesting to see how this law is carried out. It has been found that it is not at all necessary to execute it strictly, for the segregation of only the worst cases, and even of only a part of these, sufficed to produce a diminution of leprosy. Only so many infectious cases had to be sent to the leper-houses that the number of fresh cases kept regularly dininishing from year to year. Consequently the stamping-out of the disease has lasted much longer than it would have lasted if every leper had been inexorably consigned to a leper-house, as in the Middle Ages; but in this way, too, the saine purpose is gained, slowly, indeed, but without any harshness.

These examples may suffice to show what I am driving at, which is to point out that, in combating pestilences, we must strike at the root of the evil, and must not squander force in subordinate ineffective measures. Now the question is whether what has hitherto been done, and what is about to be done, against tuberculosis really strikes at the root of tuberculosis, so that it must sooner or later die.

In order to answer this question it is necessary first and foremost to inquire how infection takes place in tuberculosis. Of course, I presuppose that we understand by tuberculosis only those morbid conditions which are caused by the tubercle-bacillus.

In by far the majority of cases of tuberculosis the disease has its seat in the lung, and has also begun there. From this fact it is justly concluded that the germs of the disease, i.e. the tubercle-bacilli, must have got into the lungs by inhalation. As to the question where the inhaled tubercle-bacilli have come from, there is also no doubt. On the contrary, we know with certainty that they get into the air with the sputum of consumptive patients. This sputum, especially in advanced stages of the disease, almost always contains tubercle-bacilli, sometimes in incredible quantities. By coughing, and even speaking, it is flung into the air in little drops, i.e. in a moist condition, and can at once infect persons who happen to be near the coughers. But then it may also be pulverised when dried, in the linen or on the floor for instance, and get into the air in the form of dust.

In this manner a complete circle, a so-called circulus vitiosus, has been formed for the process of infection, from the diseased lung, which produces phlegm and pus containing tubercle-bacilli, to the formation of moist and dry particles (which, in virtue of their smallness, can keep floating a good while in the air), and finally to new infection, if particles penetrate with the air into a healthy lung and originate the disease anew. But the tuberclebacilli may get to other organs of the body in the same way, and thus originate other forms of tuberculosis. This, however, is a considerably rarer case. The sputum of consumptive people, then, is to be regarded as the main source of the infection of tuberculosis. On this point, I suppose, all are agreed. The question now arises whether there are not other sources too, copious enough to demand consideration in the combating of tuberculosis.

Great importance used to be attached to the hereditary trans. mission of tuberculosis. Now, however, it has been demonstrated by thorough investigation that, though hereditary tuberculosis is not absoluteiy non-existent, it is nevertheless extremely rare, and we are at liberty, in considering our practical measures, to leave this form of origination entirely out of account.
But another possibility of tubercular infection exists, as is generally assumed, in the transmission of the germs of the disease from tubercular animils to man. This manner of infection is generally regarded nowadays as proved, and as so frequent that it is even looked upon by not a few as the most important, and the most rigurous measure; are demanded against it. In this Congress also the discussion of the danger with which the tuherculosis of animals threatens man will play an important part. Now, as my investigations have led me to form an cpinion deviating from that which is generally accepted, I beg your permission, in consideration of the great importance of this question, to discuss it a iittle more thoroughly.

Genuine tuberculosis has hitherto been observed in almost all domestic animals, and most frequently in poultry and cattle. The tuberculosis of poultry, however, differs so much from human tuberculosis that we may leave it out of account as a possible source of infection for man. So, strictly speaking, the only kind of animal tuberculosis remaining to be considered is the tuberculosis of cattle, which, if really transferable $10 \mathrm{~mm}$, would indeed have frequent opportunities of infecting hum th beings through the drinking of the milk and the eating of the flesh of diseased animals.

Even in my first circumstantial publication on the etiolozy of tuberculosis I expressed myself regarding the identity of human tuberculosis and bovine tuberculosis with reserve. Proved facts which would have enabled me sharply to distinguish these two forms of the disease were not then at my disposal, but sure proofs of their absolute identity were equally undiscoverable, and I therefore had to leave this question undecided. In order to decide it, I have repeatedly resumed the investigations relating to it, but so long as I experimented on small animals, such as rabbits and guinea-pigs, I failed to arrive at any satisfactory result, though indications which rendered the difference of the two forms of tuberculosis probabie were not wanting. Not till the complaisance of the Ministry of Agriculture enabled me to experiment on cattle, the only animals really suitable for these investigations, did I arrive at absolutely conclusive results. Of the experiments which I have carried out during the last two years along with Prof. Schiiltz, of the Veterinary College in Berlin, I will tell you briefly some of the most important.

A number of young cattle which had stood the tuberculn test, and might therefore be regarcled as free from tuberculosis, were infected in various ways with pure cultures of tubercle-bacilli taken from cases of human tuberculosis; some of them got the tubercular sputum of consumptive patients direct. In some cases the tubercle bacilli or the sputum were injected under the skin, in others into the peritoneal cavicy, in others into the juguiar vein. Six animals were fed with tubercular sputum almost daily for seven or eight months; four repeatedly inhaled great quantities of bacilli, which were distributed in water and scattered with it in the form of spray. None of these cattle (there were nineteen of them) showed any symptoms of disease, and they gained considerably in weight. From six to eight months after the beginning of the experiments they were killed. In their internal organs not a trace of tuberculosis was found. Only at the places where the injections had been made small suppurative foci had formed, in which few tubercle-bacilli could be found. This is exactly what one finds when one injects dead tubercle-bacilli under the skin of animals liable to contagion. So the animals we experimented on were affected by the living bacilli of human tuberculosis exactly as they would have been by dead ones; they were absolutely insusceptible to them.

The result was utterly different, however, when the same experiment was made on cattle free from tuberculosis with tubercle-bacilli that came from the lungs of an animal suffering from bovine tuberculosis. After an incubation period of about a week the severest tubercular disorders of the internal organs broke out in all the affected animals. It was all one whether the infecting matter had been injected only under the skin or into the peritoneal cavity or the vascular system. High fever set in, and the animals became weak and lean; some of them died after a month and a haif to two months, others were killed in a miserably sick condition after three months. After death extensive tubercular infiltrations were fum. $d$ at the place where the injections had been made, and in the neighbouring lymphatic glands, and also far advanced alterations of the internal organs, especially the lungs and the spleen. In the cases in which the injections had been made into the peritoneal cavily the tubercular growths which are so characteristic of 
bovine tuberculosis were found on the omentum and peritoneum. In short, the cattle proved just as susceptible to infection by the bacillus of bovine tuberculosis as they had proved insusceptible to infection by the bacillus of human tuberculosis. I wish only to add that preparations of the organs of the cattle which were artificially infected with bovine tuberculosis in these experiments are exhibited in the Museum of Pathology and Bacteriology.

An almost equally striking distinction between human and bovine tuberculosis was brought to light by a feeding experiment with swine. Six young swine were fed daily for three months with the tubercular sputum of consumptive patients. Six other swine received bacilli of bovine tuberculosis with their food daily for the same period. The animals that were fed with sputum remained heaithy and grew lustily, whereas those that were fed with the bacilli of bovine tuberculosis soon became sickly, were stunted in their growth, and half of them died. After three months and a half the surviving swine were all killed and examined. Among the animals that had been fed with sputum no trace of tuberculosis was found, except here and there little nodules in the lymphatic glands of the neck, and in one case a few grey nodules in the lungs. The animals, on the other hand, which had eaten bacilli of bovine tuberculosis had, without exception (just as in the cattle experiment), severe tubercular diseases, especially tubercular infiltration of the greatly enlarged lymphatic glands of the neck and of the mesenteric glands, and also extensive tuberculosis of the lungs and the spleen.

The difference between human and bovine tuberculosis appeared not less strikingly in a similar experiment with asses, sheep and goats, into whose vascular system the two kinds of tubercle-bacilli were injected.

Our experiments, I must add, are not the only ones that have led to this result. If one studies the older literature of the subject, and collates the reports of the numerous experiments that were made in former times by Chauveau, Ginther and Harms, Bollinger and others, who fed calves, swine, and goats with tubercular material, one finds that the animals that were fed with the milk and pieces of the lungs of tubercular cattle always fell ill of tuberculosis, whereas those that received human material with their food did not. Comparative investigations regarding human and bovine tuberculosis have been made very recently in North America by Smith, Dinwiddie and Frothingham, and their result agreed with that of ours. The unambiguous and absolutely conclusive result of our experiments is due to the fact that we chose methods of infection which exclude all sources of error, and carefully avoided everything connected with the stalling, fteding and tending of the animals that might have a disturbing effect on the experiments.

Considering all these facts, I feel justified in maintaining that human tuberculosis differs from bovine, and cannot be iransmitted to cattle. It seems to me very desirable, however, that these experiments should be repeated elsewhere, in order that all doubt as to the correctness of my assertion may be removed.

I wish only to add that, owing to the great importance of this matter, the German Government has appointed a commission to make further inquiries on the subject.

But, now, how is it with the susceptibility of man to bovine tuberculosis? This question is far more important to us than that of the susceptibility of cattle to human tuberculosis, highly important as that is too. It is impossible to give this question a direct answer, because, of course, the experimental investigation of it with human beings is out of the question. Indirectly, however, we can try to approach it. It is well known that the milk and butter consumed in great cities very often contain large quantities of the bacilli of bovine tuberculosis in a living condition, as the numerous infection-experiments with such dairy products on animais have proved. Most of the inhabitants of such cities daily consume such living and perfectly virulent bacilli of bovine tuberculosis, and unintentionally carry out the experiment which we are not at liberty to make. If the bacili of bovine tuberculosis were able to infect human beings, many cases of tuberculosis caused by the consumption of alimenta containing tubercle-bacilli could not but occur among the in habitants of great cities, especially the children. And most medical men believe that this is actually the case.

In reality, however, it is not so. That a case of tuberculosis has been caused by alimenta can be assumed with certainty only when the intestine suffers first-i.e., when a so-called primary tuberculosis of the intestine is found. But such cases are extremely rare. Among many cases of tuberculosis exammed after death, I myself remember having seen primary tuberculosis of the intestine only twice. Amony the great postmorlem materia! of the Charite Hospital in Berlin ten cases of priminary tuberculosis of the intestine occurred in five years. Among 933 cases of tuberculosis in children at the Emperor and Empress Frederick's Hospital for Children, Baginsky never found tuberculosis of the intestine without simultaneous disease of the lungs and the bronchial glands. Among 3104 post mortems of tubercular children, Biedert observed only sixteen cases of primary tuberculosis of the intestine. I could cite from the literature of the subject many more statistics of the same kind, all indubitably showing that primary tuberculosis of the intestine, especially among children, is a comparatively rare disease, and of these few cases that have been enumerated, it is by no means certain that they were due to infection by bovine tuberculosis. It is just as likely that they were caused by the widely propagated bacilli of human tuberculosis, which may have got into the digestive canal in some way or other-for instance, by swallowing saliva of the mouth. Hitherto nobody could decide with certainty in such a case whether the tuberculosis of the intestine was of human or of animal origin. Now we can diagnose them. All that is necessary is to cultivate in pure culture the tuberclebacilli found in the tubercular material, and to ascertain whether they belong to bovine tuberculosis by inoculating cattle with them. For this purpose I recommend subcutaneous injection, which yields quite specially characteristic and convincing results. For half a year past I have occupied myself with such investiga. tions; but, owing to the rareness of the disease in question, the number of the cases I have been able to investigate is but small. What has hitherto resulted from this investigation does not speak for the assumption that bovine tuberculosis occurs in man.

Though the important question whether man is susceptible to bovine tuberculosis at all is not yet absolutely decided, and will not admit of absolute decision to-day or to-morrow, one is nevertheless already at liberty to say that, if such a susceptibility really exists, the infection of human beings is but a very rare occurrence. I should estimate the extent of infection by the milk and flesh of tubercular cattle, and the butter made of their milk, as hardly greater than that of hereditary transmission, and I therefore do not deem it advisable to take any measures against it.

So the only main source of the infection of tuberculosis is the sputum of consumptive patients, and the measures for the combating of tuberculosis must aim at the prevention of the dangers arising from its diffusion. Well, what is to be done in this direction? Several ways are open. One's first thought might be to consign all persons suffering from tuberculosis of the lungs, whose sputum contains tubercle-bacilli, to suitable establishments. This, however, is not only absolutely impracticable, but also unnecessary. For a consumptive who coughs out tuberclebacilli is not necessarily a source of infection on that account, so long as he takes care that his sputum is properly removed and rendered innocunus. This is certainly true of very many patients, especially in the first stages, and also of those who belong to the well-to-do classes, and are able to procure the necessary nursing. But how is it with people of very small means? Every medical man who has often entered the dwellings of the poor, and I can speak on this point from my own experience, knows how sad is the lot of consumptives and their families there. The whole family have to live in one or two small, ill-ventilated rooms. The patient is left without the nursing he needs, because the able-bodied menbers of the family must go to their work. How can the necessary cleanliness be secured under such circumstances? How is such a helpless patient to remove his sputum, so that it may do no harm? But let us go a step further and picture the condition of a poor consumptive patient's dwelling at night. The whole family sleep crowded together in one small room. However cautious he may be, the sufferer scatters the morbid matter secreted by his diseased lungs every time he coughs, and his relatives close beside him must inhale this poison. Thus whole families are infected. They die out, and awaken in the minds of those who do not know the infectiousness of tuberculosis the opinion that it is hereditary, whereas its transmission in the cases in question was due solely to the simplest process of infection, which do not strike people so much, because the consequences do not appear at once, but generally only after the lapse of years. 
Often, in such circumstances, the infection is not restricted to a single family, but spreads in densely inhabited tenementhouses to the neighbours, and then, as the admirable investigations of Biggs have shown in the case of the densely peopled parts of New York, regular nests or foci of disease are formed. But, if one investigates these matters more thoroughly, one finds that it is not poverty per se that favours tuberculosis, but the bad domestic conditions under which the poor everywhere, but especially in great cities, have to live. For, as the German statistics show, tuberculosis is less frequent, even among the poor, when the population is not densely packed together, and may attain very great dimensions among a well-to-do population when the domestic conditions, especially as regards the bedrooms, are bad, as is the case, for instance, among the inhabitants of the North Sea coast. So it is the overcrowded dwellings of the poor that we have to regard as the real breeding-places of tuberculosis; it is out of them that the disease always crops up anew, and it is to the abolition of these conditions that we must first and foremost direct our attention if we wish to attack the evil at its root, and to wage war against it with effective weapons.

This being so, it is very gratifying to see how efforts are being made in almost all countries to improve the domestic conditions of the poor. I am also convinced that these efforts, which must be promoted in every way, will lead to a considerable diminution of tuberculosis. But a long time must elapse ere essential changes can be effected in this direction, and much may be done meanwhile in order to reach the goal much more rapidly.

If we are not able at present to get rid of the danger which small and overcrowded dwellings involve, all we can do is to remove the patients from them, and, in their own interests and that of the people about them, to lodge them better; and this can be done only in suitable hospitals. But the thought of attaining this end by compulsion of any kind is very far from me; what I want is that the consumptives may be enabled to obtain the nursing they need better than they can obtain it now. At present a consumptive in an advanced stage of the disease is regarded as incurable and as an unsuitable inmate for a hospital. The consequence is that he is reluctantly admitted and dismissed as soon as possible. The patient, too, when the treatment seems to him to produce no improvement, and the expenses, owing to the long duration of his illness, weigh heavily upon him, is himself animated by the wish to leave the hospital soon. That would be altogether altered if we had special hospitals for consumptives, and if the patients were taken care of there for nothing, or at least at a very moderate rate. To such hospitals they would willingly go ; they could be better treated and cared for there than is now the case. I know very well that the execution of the project will have great difficulties to contend with, owing to the considerable outlay it entails. But very much would be gained if, at least in the existing hospitals, which have to admit a great number of consumptives at any rate, special wards were established for them, in which pecuniary facilities would be offered them. If only a considerable fraction of the whole number of consumptives were suitably lodged in this way, a diminution of infection and consequently of the sum total of tuberculosis could not fail to be the result. Permit me to remind you in this connection of what I said about leprosy. In the combating of that disease also great progress has already been made by lodging only a fair number of the patients in hospitals. The only country that possesses a considerable number of special hospitals for tubercular patients is England, and there can be no doubt that the diminution of tuberculosis in England, which is much greater than in any other country, is greatly due to this circumstance. I should point to the founding of special hospitals for consumptives and the better utilisation of the already existing hospitals for the lodging of consumptives as the most important measure in the combating of tuberculosis, and its execution opens a wide field of activity to the State, to municipalities, and to private benevolence. There are many people who possess great wealth, and would willingly give of their superfluity for the benefit of their poor and heavily afflicted fellow-creatures, but do not know how to do this in a judicious manner. Here is an opportunity for them to render a real and lasting service by founding consump. tion hospitals or purchasing the right to have a certain number of consumptive patients maintained in special wards of other hospitals free of expense.

As, however, unfortunately, the aid of the State, the muni- cipalities, and rich benefactors will probably not be forthcoming for a long time yet, we must for the present resort to other measures that may pave the way for the inain measure just referred to, and serve as a supplement and temporary substitute for it.

Among such measures I regard obligatory notification as specially valuable. In the combating of all infectious diseases it has proved indispensable as a means of obtaining certain knowledge as to their state, especially their dissemination, their increase and decrease. In the conflict with tuberculosis also we cannot dispense with obligatory notification; we need it not only in order to inform ourselves as to the dissemination of this disease, but mainly in order to learn where help and in struction can be given, and especially where the disinfection which is so urgently necessary when consumptives die or change their residences has to be effected. Fortunately it is not at all necessary to notify all cases of tuberculosis, nor even all cases of consumption, but only those that, owing to the domestic conditions, are sources of danger to the people about them. Such limited notification has already been introduced in various places, in Norway, for instance, by a special law, in Saxony by a ministerial decree, in New York and in several American towns, which have followed its example. In New York, where notification was optional at first and was afterwards made obligatory, it has proved eminently useful. It has thus been proved that the evils which it used to be feared the introduction of notification for tuberculosis would bring about need not occur, and it is devoutly to be wished that the examples I have named may very soon excite emulation everywhere.

There is another measure, closely connected with notification, viz. disinfection, which, as already mentioned, must be effected when consumptives die or change their residence, in order that those who next occupy the infected dwelling may be protected against infection. Moreover, not only the dwellings but also the infected beds and clothes of consumptives ought to be disinfected.

A further measure, already recognised on all hands as effective, is the instructing of all classes of the penple as to the infectiousness of tuberculosis, and as to the best way of protecting oneself. The fact that tuberculosis has considerably diminished in almost all civilised states of late is attributable solely to the circumstance that knowledge of the contagious character of tuberculosis has been more and more widely disseminated, and that caution in intercourse with consumptives has increased more and more in consequence. If better knowledge of the nature of tuberculosis has alone sufficed to prevent a large number of cases, this must serve us as a significant admonition to make the greatest possible use of this means, and to do more and more to bring it about that everybody may know the dangers that threaten him in intercourse with consumptives. It is only to be desired that the instructions may be made shorter and more precise than they generally are, and that special emphasis be laid on the avoidance of the worst danger of infection, which is the use of bedrooms and small ill-ventilated workrooms simultaneously with consumptives. Of course the instructions must include directions as to what consumptives have to do when they cough and how they are to treat their sputum.

Another measure, which has come into the foreground of late, and which at this moment plays to a certain extent a paramount part in all efforts for the combating of tuberculosis, works in quite another direction. I mean the founding of sanatoria for consumptives.

That tuberculosis is curable in its early stages must be regarded as an undisputed fact. The idea of curing as many tubercular patients as possible in order to reduce the number of those that reach the infectious stage of consumption, and thus to reduce the number of fresh cases, was therefore a very natural one. The only question is whether the number of persons cured in this way will be great enough to exercise an appreciable influence on the retrogression of tuberculosis. I will try to answer this question in the light of the figures at my disposal.

According to the business report of the German Central Committee for the Establishment of Sanatoria for the Cure of Consumptives, about 5500 beds will be at the disposal of these institutions by the end of 1901, and then, if we assume that the average stay of each patient will be three months, it will be possible to treat at least 20,000 patients every year. From the reports hitherto issued as to the results that have been achieved in the establishments we learn further that about 20 per cent. of the patients that have tubercle-bacilli in their sputum lose them by the treatment there. This is the only sure 
test of success, especially as regards prophylaxis. If we make this the basis of our estimates, we find that 4000 consumptives will leave these establishments annually as cured. But, according to the statistics ascertained by the German Imperial Office of Health, there are 226,000 persons in Germany above fifteen years of age who are so far gone in consumption that hospital treatment is necessary for them. Compared with this great number of consumptives the success of the establishments in question seems so small that a material influence on the retrogression of tuberculosis in general is not yet to be expected of them. But pray do not imagine that $I$ wish, by this calculation of mine, to oppose the movement for the establishment of such sanatoria in any way. I only wish to warn against the over-estimating of their importance which has recently been observable in various quarters, based apparently on the opinion that the war against tuberculosis can be waged by means of sanatoria alone, and that other measures are of subordinate value. In reality the contrary is the case. What is to be achieved by the general prophylaxis resulting from recognition of the danger of infection and the consequent greater caution in intercourse with consumptives is shown by a calculation of Cornet's regarding the decrease of mortality from tuberculosis in Prussia in the years 1889 to 1897 . Before 1889 the average was $3 \mathrm{I}^{\circ} 4$ per 10,000 , whereas in the period named it sank to $2 r \cdot 8$, which means that, in that short space of time, the number of deaths from tuberculosis was 184,000 less than was to be expected from the average of the preceding years. In New York, under the influence of the general sanitary measures directed in a simply exemplary manner by Biggs, the mortality from tuberculosis has diminished by more than 35 per cent. since 1886. And it must be remembered that both in Prussia and New Vork the progress indicated by these figures is due to the first beginnings of these measures. Considerably greater success is to be expected of their further development. Biggs hopes to have got so far in five years that in the city of New York alone the annual number of deaths from tuberculosis will be 3000 less than formerly. I take this opportunity of most urgently recommending Dr. Biggs' organ. isation to the study and imitation of all municipal sanitary authorities.

Now, I do indeed believe that it will be possible to render the sanatoria considerably more efficient. If strict care be taken that only patients be admitted for whom the treatment of those establishments is well adapted, and if the duration of the treat. ment be prolonged, it will certainly be possible to cure fifty per cent., and perhaps still more. But even then, and even if the number of the sanatoria be greatly increased, the total effect will always remain but moderate. The sanatoria will never render the other measures I have mentioned superfluous. If their number become great, however, and if they perform their functions properly, they may materially aid the strictly sanitary measures in the conflict with tuberculosis.

If now, in conclusion, we glance back once more to what has been done hitherts for the combating of tuberculosis, and forward to what has still to be done, we are at liberty to declare with a certain satisfaction that very promising beginnings have already been made. Among these I reckon the consumption hospitals of England, the legal regulations regarding notification in Norway and Saxony, the organisation created by Biggs in New York, the sanatoria, and the instruction of the people. All that is necessary is to go on developing these beginnings, to test, and if possible to increase, their influence on the diminution of tuberculosis, and wherever nothing has yet been done, to do likewise.

If we are continually guided in this enterprise by the spirit of genuine preventive medical science, if we utilise the experience gained in cunflict with other pestilences, and aim, with clear recognition of the purpose and resolute avoidance of wrong roads, at striking the evil at its root, then the battle against tuberculosis, which has been so energetically begun, cannot fail to have a victorious issue.

\section{THE ROYAL HORTICULTURAL SOCIETY'S L.IL Y CONFERENCE.}

$\mathrm{O}^{\mathrm{N}}$ July 16 the Royal Horticultural Society held a conference on "lilies." Although by no means organised upon the same scale as the meeting was two years ayo, when hybridisation was discussed, the one under consideration proved, nevertheless, of some importance and much interest.

NO. I 656 , vOL. 64]
An exhibition of lilies was also arranged for the same day and the following one, in the Society's Gardens at Chiswick, where the conference took place. The number of plants shown was not large, but taking into consideration the fact that many species had done flowering, while others were nol yet in blossom, the series collected together may he put down as a fairly representative one. Possibly more examples might have been displayed if growers had had a little longer notice given to them.

As soon as the inevitable luncheon was cleared away from the tent, the chair was taken by Mr. H. J. Elwes, F.R.S., who had returned from abroad for the purpuse. He was also put down upon the programme to give an address on lilies, dis. covered or brought into cultivation since the issue of his well known monograph upon these plants.

The chairman, however, deputed this part of his task to $M r$. I. G. Baker, F.R.S., and contented himself with making a series of interesting comments upon the various froints alluded to by the different speakers. Mr. Baker's contribution being mostly descriptive, he merely alluded briefly in passing to the lilies discovered and in several cases taken up by horticulturists during the last twenty years.

The plants concerned came chiefly from Upper Burma and Central and Western China. Some of the new martagons, however, were discovered in California and North Carolina. Species from the first-mentioned locality were due to the efforts of Sir Henry Collett, while the Chinese ones were collected by French missionaries and by Dr. Henry, who was present and spoke at the conference.

Among the many species and varieties mentioned, one may allude to Lilium mirabile, found by one of the missionaries in Western China, and which is unique among lilies in possessing as it does a centrifugal inflorescence; in all others, the lowermost flowers upon the stalk are the first to open. L. lowe $i$ was shown to be the same thing as L. bakerianum, the latter name having priority.

Dr. Henry, who sent home no less than 13.700 specimens of plants, was the next to speak. He was not able to pay special attention to any one kind of plants, so had nothing very particular to say about the habitats of lilies.

He described a day's journey in Western China as up one side of a mountain and down again into the valley on the other side. This speaker also pointed out that there were thousands and thousands of these valleys, each with its own flora, and that there was ample room in the tracts of country he traversed for a hundred collectors of plants.

After several contributior.s had been made to the meeting, Mr. George Massee had something to say upon the fungoid diseases to which lilies are liable. The chairman had already pointed out how the scientific man was indebter to the professional horticulturist, who introduced and flowered many species that the former would otherwise be unable to figure from living species when monographing a genus, and, again, how the practical man gains through the work of the botanist. Mr. Massee showed very forcibly how the gardener does not profit as much as he might from the labours of the mycologist. Great intelligence was granted to the horticulturist, but within a certain circle; this did not, however, include an appreciation of many simple methods of prevention. For instance, Mr. Massee pointed out that by merely adding a little kainite or Strasburgh fertiliser the most serious "lily disease," which, when it has once taken a hold, is incurable, can be successlully warded off.

When the whole series of papers is printed, growers of lilies should find much intormation of use to them, while botanists should be grateful to have their knowledge of the species and varieties of lilies brought once more up to date.

WILFRED MARK WEBB.

\section{THE PROPERTIES OF STEEL CASTINGS.}

THE first of a series of papers on the result of researches carried out during several years at the Sheffield University College was read by Prof. J. O. Arnold before the Iron and Steel Insitute on May 9.

This preliminary paper dealt only with castings composed mainly of iron and carbon. It was shown that such a composition was unsuitable to meet the demands of engineers. The maximum stress recorded in the series was 32.42 tons per sq. in., associated with an elongation of only 2 per cent., whilst the maximum ductility obtained was an elongation of 46 per 